\title{
Etiology and therapeutic outcomes of children with gonadotropin-independent precocious puberty
}

\author{
Eungu Kang, MD, \\ Ja Hyang Cho, MD, \\ Jin-Ho Choi, MD, \\ Han-Wook Yoo, MD, PhD
}

Department of Pediatrics, Asan Medical Center Children's Hospital, University of Ulsan College of Medicine, Seoul, Korea
Purpose: This study was performed to investigate the etiology, clinical features, and outcomes of patients with gonadotropin-independent precocious puberty (GIPP). Methods: The study included 16 patients (14 female and 2 male patients) who manifested secondary sexual characteristics, elevated sex hormones, or adrenal androgens with prepubertal luteinizing hormone levels after gonadotropin releasing hormone stimulation diagnosed between May 1994 and December 2015. Patients with congenital adrenal hyperplasia were excluded. Clinical features, laboratory findings, treatment modalities, and outcomes were retrospectively reviewed.

Results: The median age at diagnosis was 2.6 years (range, $0.7-7.9$ years) and median follow-up duration was 4.6 years (range, 1 month-9.8 years). Patients with McCune-Albright syndrome $(n=5)$ and functional ovarian cysts $(n=4)$ presented with vaginal bleeding and elevated estradiol levels $(23.3 \pm 17.5 \mathrm{pg} / \mathrm{mL})$; adrenocortical tumors $(n=4)$ with premature pubarche and elevated dehydroepiandrosterone sulfate levels $(87.2-6,530 \mu \mathrm{g} / \mathrm{dL})$; and human chorionic gonadotropin (hCG)producing tumor $(n=1)$ with premature pubarche and elevated $\beta$-human chorionic gonadotropin levels $(47.4 \mathrm{mlU} / \mathrm{mL})$. Two patients were idiopathic. Six patients transited to gonadotropin-dependent precocious puberty median 3.3 years (range, 0.3-5.1 years) after the onset of GIPP. Initial and follow-up height standard deviation scores $(0.99 \pm 0.84$ vs. $1.10 \pm 1.10, P=0.44)$ and bone age advancement $(1.49 \pm 1.77$ years vs. $2.02 \pm 1.95$ years, $P=0.06$ ) were not significantly different.

Conclusion: The etiologies of GIPP are heterogeneous, and treatment and prognosis is quite different according to the etiology. Efficacy of treatment with aromatase inhibitors needs to be evaluated after long-term follow-up.

Keywords: Precocious puberty, Gonadotropin-independent, Etiology, Treatment outcome

\section{Introduction}

Received: 26 January, 2016

Revised: 5 April, 2016

Accepted: 12 April, 2016

Address for correspondence: Han-Wook Yoo, MD, PhD

Department of Pediatrics, Asan

Medical Center Children's Hospital,

University of Ulsan College of

Medicine, 88 Olympic-ro 43-gil,

Songpa-gu, Seoul 05505, Korea

Tel: +82-2-3010-3374,

Fax: +82-2-473-3725,

E-mail: hwyoo@amc.seoul.kr
Precocious puberty is defined as the development of secondary sexual characteristics before the age of 8 years in girls and 9 years in boys ${ }^{1)}$. Precocious puberty is clinically categorized into gonadotropin releasing hormone $(\mathrm{GnRH})$-dependent and $\mathrm{GnRH}$-independent processes according to the existence of hypothalamic-pituitary-gonadal axis activation. Central or gonadotropin-dependent precocious puberty (GDPP) results from activation of the hypothalamic-pituitary-gonadal axis by a variety of central nervous system abnormalities ${ }^{2,3)}$.

Peripheral or gonadotropin-independent precocious puberty (GIPP) is caused by excessive sex hormones produced in the gonads or adrenal glands, $\beta$-human chorionic gonadotropin $(\beta$-hCG)-secreting tumors, or exposure to exogenous sex hormones. The common etiologies of excessive production of sex hormones by the gonads include McCuneAlbright syndrome (MAS), functional ovarian cysts (FOCs), Leydig cell tumors, or familial 
male-limited precocious puberty. Adrenal origin of excess androgen production is caused by androgen-secreting tumors or congenital adrenal hyperplasia ${ }^{3,4)}$. Treatment of GIPP is directed at the underlying pathology. However, in MAS or familial male-limited precocious puberty, treatments using aromatase inhibitors and antiestrogens or antiandrogens have demonstrated partial efficacy in reducing the growth rate and improving predicted adult height ${ }^{5-7)}$.

GIPP is much less common than GDPP, regardless of the etiology. GDPP has a predictable physiologic and clinical course, whereas the pathophysiology and clinical manifestations of GIPP are heterogeneous according to its etiology. Appropriate treatment modalities and their efficacy in GIPP are obscure, and the long-term prognosis also remains uncertain. Therefore, this study aimed to determine the etiology, clinical features, and treatment outcome of patients with GIPP according to each etiology.

\section{Materials and methods}

\section{Patients}

This study included 16 patients with GIPP, who were diagnosed between May 1994 and December 2015 at Asan Medical Center Children's Hospital, Seoul, Korea. Fourteen female patients initially presented with breast or pubic hair development before the age of 8 years, or vaginal bleeding before the age of 9.5 years. Two male patients presented with penile enlargement or pubic hair development before the age of 9 years. Patients with congenital adrenal hyperplasia were excluded from the study because the incidence of precocious puberty in children congenital adrenal hyperplasia is much higher than other causes of GIPP, and clinical features were heterogeneous according to the phenotypes, age at diagnosis, and treatment.

\section{Methods}

The patients' clinical parameters, such as presenting symptoms, etiology, laboratory and radiologic findings, treatment, and clinical course, were reviewed retrospectively.

Basal luteinizing hormone (LH), follicle stimulating hormone (FSH), estradiol (in females), testosterone (in males or females with pubarche), dehydroepiandrosterone sulfate (DHEA-S, in patients with pubarche) and $\beta$-hCG (in males) were measured in patients who presented with breast or pubic hair development.

Pelvic ultrasonography was performed in female patients with elevated estradiol levels. Adrenal ultrasonography or computed tomography was carried out in patients with pubic hair development or elevated DHEA-S levels. Tc-99m 3,3-diphosphono-1,2-propanedicarboxylic acid bone scan was done to investigate fibrous dysplasia in patients with ovarian cysts and café-au-lait spots. The screening for GDPP were performed when the patients revealed accelerated linear growth or advanced bone age (advanced bone age of at least 1 year relative to chronologic age).

The sex hormone or adrenal androgen levels were elevated in the patients, and the peak LH level was less than $5 \mathrm{mIU} / \mathrm{mL}$ after the stimulation of intravenous GnRH (Relefact, Sanofi-Aventis, Frankfurt am Main, Germany) at a dose of $2.5 \mu \mathrm{g} / \mathrm{kg}$ (maximum $100 \mu \mathrm{g})$. The diagnosis of GDPP were made when the peak LH level was higher than $5 \mathrm{mIU} / \mathrm{mL}$ after the stimulation of intravenous $\mathrm{GnRH}^{3)}$

Height was expressed as standard deviation score (SDS) according to the normative data from Korean references ${ }^{8)}$. $\mathrm{LH}$ (LHsp-IRMA, BioSource Europe S.A, Nivelles, Belgium), FSH (FSH-IRMA, BioSource Europe S.A,), and $\beta$-hCG (RIAKEY, Shin Jin Medics Inc, Goyang, Korea) were measured with immunoradiometric assays. DHEA-S, estradiol (in females), and testosterone (in males or females with pubic hair development) were measured with radioimmunoassays (Coat-A-Count, Diagnostic Products Corp., Los Angeles, CA, USA). The intraassay coefficients of variation for $\mathrm{LH}$ were $3.9 \%$ and $1.4 \%$ for the mean concentration of $6.6 \mathrm{mIU} / \mathrm{mL}$ and $46.6 \mathrm{mIU} / \mathrm{mL}$, respectively. The interassay coefficients of variation for $\mathrm{LH}$ were $8.0 \%$ and $3.4 \%$ for the mean concentration of $5.9 \mathrm{mIU} /$ $\mathrm{mL}$ and $57.6 \mathrm{mIU} / \mathrm{mL}$, respectively. The intra-assay coefficients of variation for $\mathrm{FSH}$ were $1.8 \%, 2.0 \%$, and $1.1 \%$ for the mean concentration of 4.0, 9.0, and $50.7 \mathrm{mIU} / \mathrm{mL}$, respectively. The interassay coefficients of variation for FSH were $4.4 \%$ and $2.4 \%$ for the mean concentration of 15.0 and $41.9 \mathrm{mIU} / \mathrm{mL}$, respectively. The detection limits of the assay were $0.2 \mathrm{mIU} / \mathrm{mL}$ for $\mathrm{LH}, 0.1 \mathrm{mIU} / \mathrm{mL}$ for FSH, $8 \mathrm{pg} / \mathrm{mL}$ for estradiol, and $0.03 \mathrm{ng} /$ $\mathrm{mL}$ for testosterone. Bone age was assessed with the GreulichPyle method ${ }^{9)}$. The results are represented as mean \pm standard deviation in normative data and median (range) in skewed data. Comparison of initial and follow-up height SDS and bone age advancement were analyzed with the Wilcoxon signed-rank test. Statistical analyses were performed using IBM SPSS Statistics ver. 21.0 (IBM Co., Armonk, NY, USA).

\section{Results}

\section{Etiology and presenting symptoms of GIPP}

GIPP was diagnosed at the median age of 2.6 years (range, 0.7-7.9 years), and the median duration of follow-up was 4.6 years (range, 1 month-9.8 years). Among the 7 female patients who presented with vaginal bleeding, 4 had MAS and 3 had FOCs. The diagnosis of MAS was made when the patient showed at least 2 of classic triad including precocious puberty, café-au-lait spot, and polyostotic fibrous dysplasia. Pubic hair had developed in 4 female patients with adrenocortical tumors (adrenocortical carcinoma in 2 and adrenocortical oncocytic adenoma in 2), and in 1 male patient with $\beta$-hCG producing germinoma. Three patients presented with breast development: 1 with MAS, 1 with FOCs, and 1 that was idiopathic. One male patient presented with elongated penile length of unknown 
etiology (Table 1).

\section{Laboratory and image findings}

Laboratory testing revealed suppressed LH and FSH levels with elevated estradiol in females or testosterone in males (Table 2). In 4 patients with adrenocortical tumors, DHEA-S levels were markedly elevated (median, $936.5 \mu \mathrm{g} / \mathrm{mL}$; range, $87.2-$ $6530 \mu \mathrm{g} / \mathrm{mL}$ ). Peak LH levels were less than $5 \mathrm{mIU} / \mathrm{mL}$, and there were FSH-predominant patterns after exogenous GnRH

Table 1. The etiology of goandotropin-independent precocious puberty and the clinical characteristics of the patients at diagnosis

\begin{tabular}{|c|c|c|c|c|c|c|}
\hline No. & Diagnosis & Age (yr) & Sex & Presenting symptom & Bone age (yr) & Height-SDS \\
\hline 1 & MAS & 5.3 & $F$ & Vaginal bleeding & 5.7 & 0.65 \\
\hline 2 & MAS & 4.3 & $\mathrm{~F}$ & Vaginal bleeding & 4.5 & 1.42 \\
\hline 3 & MAS & 1.7 & $\mathrm{~F}$ & Vaginal bleeding & 1.7 & 0.37 \\
\hline 4 & MAS & 2.3 & $\mathrm{~F}$ & Vaginal bleeding & 3.0 & -0.06 \\
\hline 5 & MAS & 2.5 & $\mathrm{~F}$ & Breast development & 3.5 & 0.81 \\
\hline 6 & Ovarian cyst & 3.8 & $\mathrm{~F}$ & Vaginal bleeding & 6.8 & 0.95 \\
\hline 7 & Ovarian cyst & 2.9 & $\mathrm{~F}$ & Vaginal bleeding & 3.5 & 1.73 \\
\hline 8 & Ovarian cyst & 6.8 & $\mathrm{~F}$ & Vaginal bleeding & 6.8 & -0.38 \\
\hline 9 & Ovarian cyst & 4.9 & $\mathrm{~F}$ & Breast development & 5.5 & 1.21 \\
\hline 10 & Adrenocortical oncocytic adenoma & 2.4 & $\mathrm{~F}$ & Pubic hair development & 7.8 & 3.26 \\
\hline 11 & Adrenocortical oncocytic adenoma & 2.3 & $\mathrm{~F}$ & Pubic hair development & 5.0 & 0.63 \\
\hline 12 & Adrenocortical carcinoma & 2.6 & $\mathrm{~F}$ & Pubic hair development & 3.0 & 1.88 \\
\hline 13 & Adrenocortical carcinoma & 0.7 & $\mathrm{~F}$ & Pubic hair development & & 0.82 \\
\hline 14 & B-hCG producing germinoma & 7.9 & M & Pubic hair development & 13.0 & 0.80 \\
\hline 15 & Idiopathic & 1.1 & $\mathrm{~F}$ & Breast development & 1.5 & 0.67 \\
\hline 16 & Idiopathic & 4.5 & M & Elongated penile length & 6.0 & 1.09 \\
\hline
\end{tabular}

MAS, McCune-Albright syndrome; SDS, standard deviation score; $\beta$-hCG, $\beta$-human chorionic gonadotropin.

A
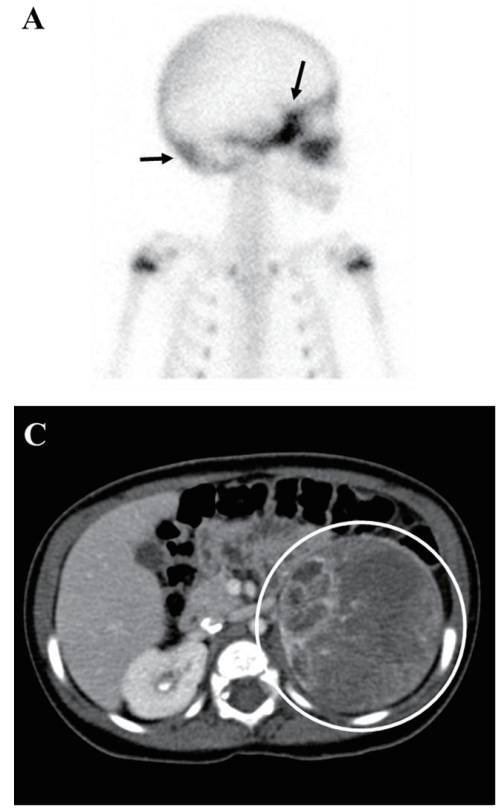
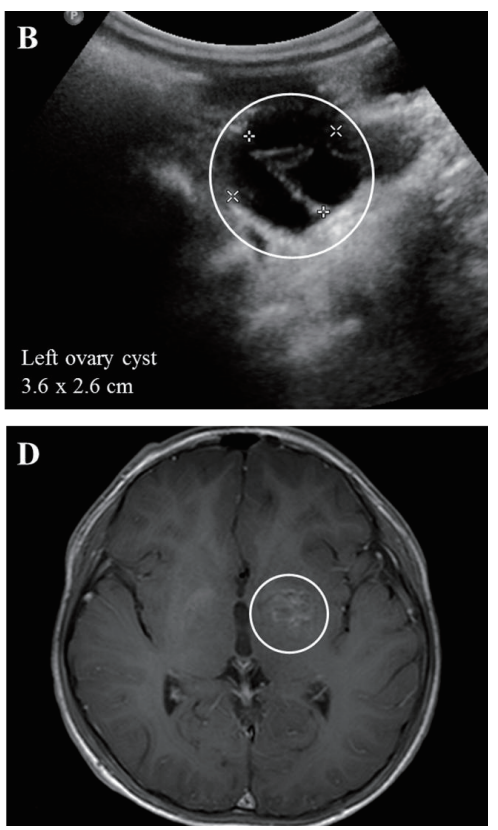

Fig. 1. Imaging findings of patients with gonadotropin-independent precocious puberty. (A) Tc99m 3,3-diphosphono-1,2-propanedicarboxylic acid bone scan (right lateral view) of a patient with McCune-Albright syndrome (MAS) (patient 5) revealed diffuse symmetrical increased uptake along the skull base and occipital bone (arrows), suggesting fibrous dysplasia. (B) 3.6×2.6-cmsized left ovarian cyst (circle) demonstrated by pelvic ultrasonography in a patient with MAS. (C) Abdominal computed tomography demonstrated an 8.4×6.4-cm left adrenal gland mass with heterogeneous enhancement and calcification (circle) in an 8-month-old girl with premature pubarche (patient 13). (D) Brain magnetic resonance imaging revealed a $2.2 \times 1.9 \times 2.2-\mathrm{cm}$ lobulated mass involving the left basal ganglia (circle) with thickening of the pituitary stalk, indicating germinoma in an 8-year-old boy with premature adrenarche (patient 14). 
Table 2. Initial laboratory and radiologic findings of patients with GIPP

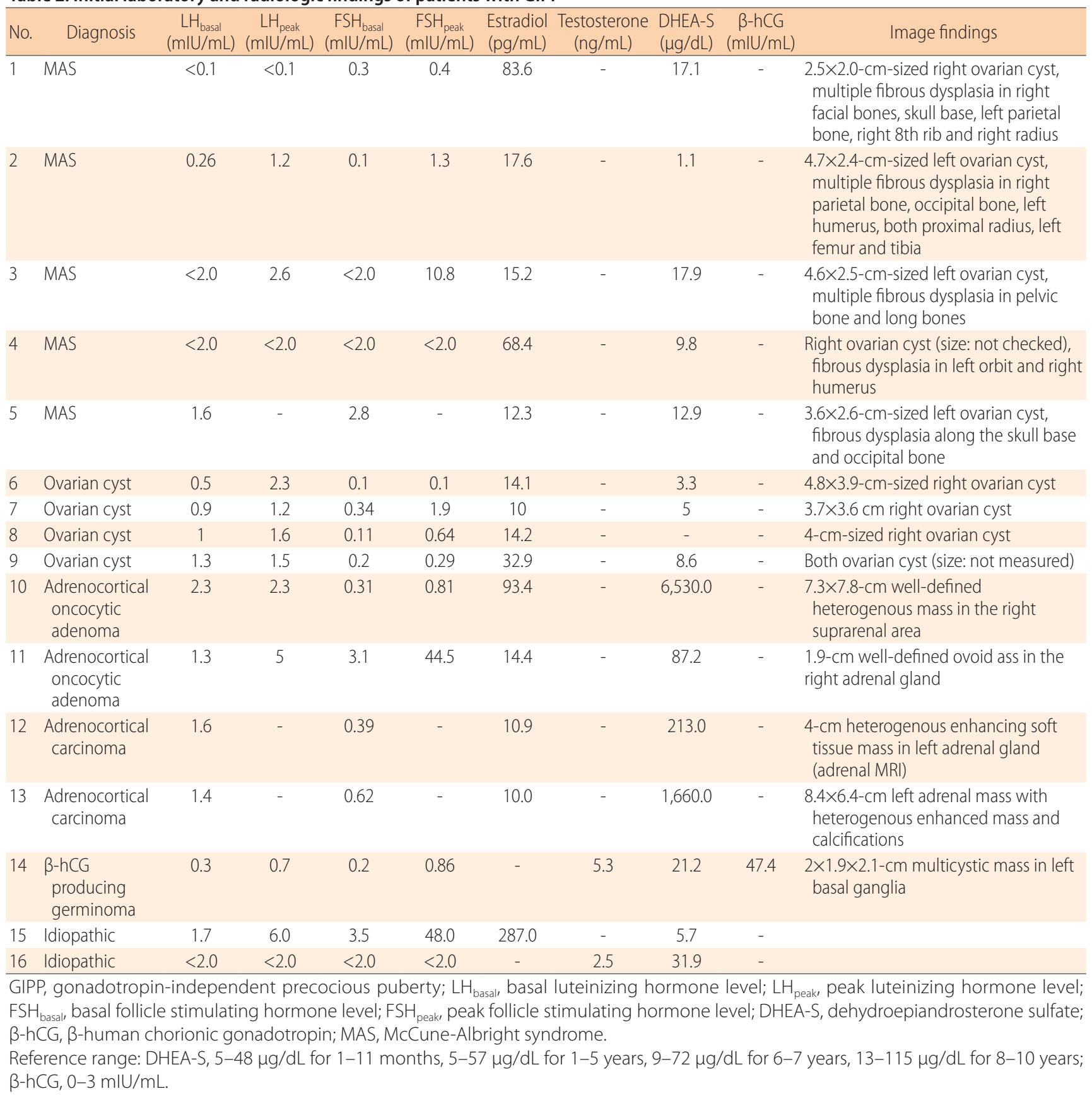

stimulation (Table 2). GnRH stimulation testing was not done in 3 patients, including 1 with MAS who presented with breast development at the age of 2.5 years, and 2 with adrenocortical carcinomas diagnosed at the ages of 8 months and 2.6 years, respectively.

The median value of difference between bone age and chronological age at the time of diagnosis in the patients with MAS, FOCs, adrenal tumors, and $\beta$-hCG producing germinoma was 0.4 years (range, $0-1$ years), 0.6 years (range, $0-3$ years), 2.8 years (range, $0.4-5.4$ years), and 5.1 years, respectively. The radiologic findings in the patients with MAS, adrenocortical carcinoma, and $\beta$-hCG producing germinoma are shown in Table 2 and Fig. 1. Two patients (patients 14 and 15) with markedly elevated sex hormone who diagnosed as idiopathic GIPP did not identified any abnormalities in tumor markers and radiologic evaluation.

\section{Treatment and outcomes}

Five patients with MAS and 3 with FOCs were treated with letrozole. Recurrent vaginal bleeding (median, 0.8 episodes/ yr; range, 0.3-1.9 episodes/yr) was observed despite treatment with the aromatase inhibitor. Ovarian cystectomy was not 
Table 3. Treatment and clinical course of the patients with GIPP

\begin{tabular}{|c|c|c|c|c|c|c|}
\hline No. & Diagnosis & Treatment and clinical course & $\begin{array}{l}\text { Age at last } \\
\text { follow-up (yr) }\end{array}$ & $\begin{array}{l}\text { Follow-up } \\
\text { duration (yr) }\end{array}$ & Bone age (yr) & Height-SDS \\
\hline 1 & MAS & $\begin{array}{l}\text { Letrozole, transit to GDPP } \\
\text { after } 2.7 \text { years }\end{array}$ & 9.5 & 4.1 & 11.5 & 0.91 \\
\hline 2 & MAS & $\begin{array}{l}\text { Letrozole, transit to GDPP } \\
\text { after } 4.3 \text { years }\end{array}$ & 12.8 & 8.6 & 12.5 & 1.05 \\
\hline 3 & MAS & Letrozole & 9.4 & 7.8 & 11.5 & -0.69 \\
\hline 4 & MAS & Letrozole & 4.6 & 2.3 & 6.8 & 0.53 \\
\hline 5 & MAS & Letrozole & 4.2 & 1.7 & 5.0 & 1.05 \\
\hline 6 & Ovarian cyst & $\begin{array}{l}\text { Letrozole, spontaneous } \\
\text { resolution of ovarian cyst }\end{array}$ & 8.1 & 4.3 & 11.0 & 1.21 \\
\hline 7 & Ovarian cyst & Transit to GDPP after 5.1 years & 8.6 & 5.7 & 10.0 & 3.05 \\
\hline 8 & Ovarian cyst & $\begin{array}{l}\text { Letrozole, spontaneous } \\
\text { resolution of ovarian cyst }\end{array}$ & 13.3 & 6.5 & 13.5 & -0.55 \\
\hline 9 & Ovarian cyst & $\begin{array}{l}\text { Letrozole, transit to GDPP } \\
\text { after } 3.0 \text { years }\end{array}$ & 10.3 & 5.3 & 11.5 & 1.98 \\
\hline 10 & $\begin{array}{l}\text { Adrenocortical } \\
\text { oncocytic adenoma }\end{array}$ & $\begin{array}{l}\text { Tumor excision, transit to GDPP } \\
\text { after } 4 \text { months }\end{array}$ & 3.8 & 1.3 & 10.5 & 3.14 \\
\hline 11 & $\begin{array}{l}\text { Adrenocortical } \\
\text { oncocytic adenoma }\end{array}$ & Tumor excision & 7.3 & 5.0 & 8.8 & 0.83 \\
\hline 12 & Adrenocortical carcinoma & $\begin{array}{l}\text { Tumor excision, transit to GDPP } \\
\text { after } 3.5 \text { years }\end{array}$ & 12.4 & 9.8 & 13.5 & 1.07 \\
\hline 13 & Adrenocortical carcinoma & Tumor excision & 3.7 & 2.9 & 3.5 & 0.74 \\
\hline 14 & $\beta-h C G$ producing germinoma & Chemotherapy & 8.7 & 0.7 & 13.5 & 1.18 \\
\hline 15 & Idiopathic & Letrozole & 8.6 & 7.5 & 8.8 & -0.17 \\
\hline 16 & Idiopathic & Lost to follow-up & 5.3 & 0.7 & 5.0 & 2.19 \\
\hline
\end{tabular}

done in any patients in spite of the recurrent vaginal bleeding. Tumor excision was performed for all adrenocortical tumors. The monitoring of tumor recurrence was done by DHEA-S level and imaging study of adrenal glands. Premature pubarche disappeared after tumor excision and there was no recurrence of tumor. The chemotherapy was administered for the $\beta$-hCG producing germinoma.

After the diagnosis of GIPP, the patients were evaluated for pubertal stage, growth velocity and bone age every 6 months. The patients who revealed rapid linear growth and advanced bone age were screened for GDPP. During the follow-up period, 6 patients ( 2 with MAS, 2 with FOCs, and 2 with adrenocortical tumors) transited to GDPP at the median age of 8.0 years (range, 2.8-8.6 years) and median 3.3 years (range, $0.3-5.1$ years) after the onset of GIPP. Initial and last height-SDS $(0.99 \pm 0.84$ vs. $1.10 \pm 1.10, P=0.44)$ and bone age advancement $(1.49 \pm 1.77$ years vs. $2.02 \pm 1.95$ years, $P=0.06$ ) were not significantly different (Table 3).

\section{Discussion}

In this study, the MAS and FOCs were relatively common cause of GIPP. In these cases, the typical presenting symptom of precocious puberty was vaginal bleeding, which represents withdrawal bleeding following the resolution of estrogenproducing cysts. These patients did not reveal significant bone age advancement at diagnosis. The patients with adrenocortical tumors were presented with virilization and associated with adrenal androgens. There was no tumor recurrence after complete resection.

MAS is a genetic disorder characterized by the triad of caféau-lait spots, polyostotic fibrous dysplasia, and precocious puberty. The manifestations of MAS are due to somatic activating mutation of the GNAS gene encoding the Gsa protein, which is involved in intracellular cAMP production ${ }^{10)}$. GIPP occurs in $50 \%-90 \%$ of female patients with $\mathrm{MAS}^{5,11,12)}$. The natural history of precocious puberty in MAS is extremely heterogeneous; some patients experience waxing and waning breast development with or without isolated episodes of vaginal bleeding and minimal bone age advancement, while others experience progressive pubertal maturation and frequent bleeding $^{5)}$. Recurrent exposure to sex hormones accelerates maturation of the epiphyseal plate, resulting in compromised final height, while deformities and fractures of the long bones are caused by polyostotic fibrous dysplasia ${ }^{13)}$.

The long-term management of GIPP in MAS is not established. Girls with infrequent vaginal bleeding can often be observed without treatment. In case of progressive forms of precocious puberty, medications that decrease estrogen biosynthesis or blunt the effects of estrogen should be considered ${ }^{5)}$. In a few studies, letrozole (aromatase inhibitor), tamoxifen (selective estrogen receptor modulator), or fulvestrant (estrogen 
receptor antagonist) were effective in decreasing the rate of skeletal maturation and vaginal bleeding ${ }^{14-16)}$. However, most of these agents have demonstrated inadequate efficacy. In the present study, most patients with MAS or FOCs were treated with letrozole. However, the efficacy was uncertain due to the duration of treatment being short and inconsistent in each patient. None of the subjects' final adult height was measured, therefore, the efficacy of this treatment in GIPP patients needs to be evaluated after long-term follow-up.

Childhood adrenocortical tumors are another entity causing GIPP. Adrenocortical tumors are rare in childhood, but they are the most frequent extracranial tumors that cause GIPP ${ }^{17)}$. The majority of adrenocortical tumors in childhood are functional, and the most common presenting symptom is virilization alone or in combination with other signs of overproduction of adrenal hormones, occurring in $80 \%-95 \%$ of patients ${ }^{18-20)}$. In particular, adrenocortical carcinoma should be suspected in girls younger than 6 years old who manifest pubarche with highly elevated DHEA-S levels ${ }^{20-22)}$. In the present study, 4 female patients with adrenal tumors demonstrated virilization and markedly elevated serum DHEA-S levels, indicating excessive adrenal androgen production. In our patients, there were no features of Cushing syndrome or mineralocorticoid excess. Age younger than 4 years, virilizing tumor, small tumor size, and localized disease are associated good prognosis in pediatric adrenocortical tumor. The survival rate is approximately $80 \%-90 \%$ in the patients with better prognostic factors ${ }^{20,23)}$.

Long-term exposure to sex hormones due to the GnRHindependent process can lead to GDPP, necessitating GnRH agonist treatment. This occurs after initiation of treatment for the underlying disease, particularly in patients with significantly advanced bone age. Once the negative feedback effect of pubertal sex steroid concentrations is removed, the hypothalamic-pituitary-gonadal axis can subsequently be activated. However, the mechanisms are not yet well understood $^{3,4,24,25)}$. In the present study, transition to GDPP occurred in 6 patients, approximately 3.2 years after the diagnosis of GIPP. This indicates that surveillance for GDPP should be a part of the follow-up in patients with GIPP.

In conclusion, the etiologies of GIPP are heterogeneous, and treatment and prognosis is quite different according to the etiology. It is important to consider the rare etiologies of GIPP and correct the underlying pathology based on the exact diagnosis in patients with GIPP. The medical treatment can be considered although long-term efficacy of these treatments needs to be evaluated. Also, the regular monitoring of GDPP is required during the follow-up of the patients with GIPP.

\section{Conflict of interest}

No potential conflict of interest relevant to this article was reported.

\section{References}

1. Carel JC, Eugster EA, Rogol A, Ghizzoni L, Palmert MR; ESPE-LWPES GnRH Analogs Consensus Conference Group, et al. Consensus statement on the use of gonadotropin-releasing hormone analogs in children. Pediatrics 2009; 123:e752-62.

2. Carel JC, Léger J. Clinical practice: precocious puberty. N Engl J Med 2008;358:2366-77.

3. Fuqua JS. Treatment and outcomes of precocious puberty: an update. J Clin Endocrinol Metab 2013;98:2198-207.

4. Eugster EA. Peripheral precocious puberty: causes and current management. Horm Res 2009;71 Suppl 1:64-7.

5. Collins MT, Singer FR, Eugster E. McCune-Albright syndrome and the extraskeletal manifestations of fibrous dysplasia. Orphanet J Rare Dis 2012;7 Suppl 1:S4.

6. Eugster EA, Rubin SD, Reiter EO, Plourde P, Jou HC, Pescovitz $\mathrm{OH}$, et al. Tamoxifen treatment for precocious puberty in McCune-Albright syndrome: a multicenter trial. J Pediatr 2003; 143:60-6.

7. Kreher NC, Pescovitz OH, Delameter P, Tiulpakov A, Hochberg Z. Treatment of familial male-limited precocious puberty with bicalutamide and anastrozole. J Pediatr 2006;149:416-20.

8. Korea Centers for Disease Control and Prevention, Division of Chronic Disease Surveillance, Committee for the Development of Growth Standard for Korean Children and Adolescents; Korean Pediatric Society, Committee for School Health and Public Health Statistics. 2007 Korean children and adolescents growth standard (commentary for the development of 2007 growth chart). Cheongju: Korea Centers for Disease Control and Prevention, Division of Chronic Disease Surveillance, 2007.

9. Greulich W, Pyle I. Radiographic atlas of skeletal development of the hand and wrist. 2nd ed. Stanford (CA): Stanford University Press, 1955.

10. Weinstein LS, Shenker A, Gejman PV, Merino MJ, Friedman E, Spiegel AM. Activating mutations of the stimulatory $G$ protein in the McCune-Albright syndrome. N Engl J Med 1991;325:1688-95.

11. Lumbroso S, Paris F, Sultan C; European Collaborative Study. Activating Gsalpha mutations: analysis of 113 patients with signs of McCune-Albright syndrome: a European Collaborative Study. J Clin Endocrinol Metab 2004;89:2107-13.

12. Mieszczak J, Eugster EA. Treatment of precocious puberty in McCune-Albright syndrome. Pediatr Endocrinol Rev 2007;4 Suppl 4:419-22.

13. Völkl TM, Dörr HG. McCune-Albright syndrome: clinical picture and natural history in children and adolescents. J Pediatr Endocrinol Metab 2006;19 Suppl 2:551-9.

14. de G Buff Passone C, Kuperman H, Cabral de MenezesFilho H, Spassapan Oliveira Esteves L, Lana Obata Giroto R, Damiani D. Tamoxifen improves final height prediction in girls with McCune-Albright syndrome: a long follow-up. 
Horm Res Paediatr 2015;84:184-9.

15. Feuillan P, Calis K, Hill S, Shawker T, Robey PG, Collins MT. Letrozole treatment of precocious puberty in girls with the McCune-Albright syndrome: a pilot study. J Clin Endocrinol Metab 2007;92:2100-6.

16. Sims EK, Garnett S, Guzman F, Paris F, Sultan C, Eugster EA, et al. Fulvestrant treatment of precocious puberty in girls with McCune-Albright syndrome. Int J Pediatr Endocrinol 2012;2012:26

17. Wendt S, Shelso J, Wright K, Furman W. Neoplastic causes of abnormal puberty. Pediatr Blood Cancer 2014;61:66471.

18. Sabbaga CC, Avilla SG, Schulz C, Garbers JC, Blucher D. Adrenocortical carcinoma in children: clinical aspects and prognosis. J Pediatr Surg 1993;28:841-3.

19. Ciftci AO, Senocak ME, Tanyel FC, Büyükpamukçu N. Adrenocortical tumors in children. J Pediatr Surg 2001;36: 549-54.

20. Michalkiewicz E, Sandrini R, Figueiredo B, Miranda EC, Caran E, Oliveira-Filho AG, et al. Clinical and outcome characteristics of children with adrenocortical tumors: a report from the International Pediatric Adrenocortical Tumor Registry. J Clin Oncol 2004;22:838-45.

21. Fassnacht M, Kenn W, Allolio B. Adrenal tumors: how to establish malignancy? J Endocrinol Invest 2004;27:387-99.

22. Wolthers OD, Cameron FJ, Scheimberg I, Honour JW, Hindmarsh PC, Savage MO, et al. Androgen secreting adrenocortical tumours. Arch Dis Child 1999;80:46-50.

23. McAteer JP, Huaco JA, Gow KW. Predictors of survival in pediatric adrenocortical carcinoma: a Surveillance, Epidemiology, and End Results (SEER) program study. J Pediatr Surg 2013;48:1025-31.

24. Foster CM, Comite F, Pescovitz OH, Ross JL, Loriaux DL, Cutler GB Jr. Variable response to a long-acting agonist of luteinizing hormone-releasing hormone in girls with McCune-Albright syndrome. J Clin Endocrinol Metab 1984;59:801-5.

25. Pescovitz OH, Comite F, Cassorla F, Dwyer AJ, Poth MA, Sperling MA, et al. True precocious puberty complicating congenital adrenal hyperplasia: treatment with a luteinizing hormone-releasing hormone analog. J Clin Endocrinol Metab 1984;58:857-61. 